\title{
Clinical Results of Intravesical Application of BCG and Interferon- $\alpha$ 2A for Superficial Bladder Tumor Prophylaxis
}

\author{
Aydın İsmet Hazar (1), Can Arat (D), Osman Ceylan (1), Vedat Çalışır(i) \\ Clinic of Urology, University of Health Sciences Gaziosmanpaşa Taksim Training and Research Hospital, İstanbul, Turkey \\ Cite this article as: Hazar Ai, Arat C, Ceylan O, Çalışır V. Clinical Results of Intravesical Application of BCG and Interferon- $\alpha$ 2A for Superficial \\ Bladder Tumor Prophylaxis. JAREM 2018; 8: 39-42.
}

\begin{abstract}
Objective: Transurethral resection (TUR) has been used in the treatment of non-muscle invasive bladder cancer. These tumors are recurrent and have a risk of progression despite complete resection. We evaluated the efficiency of intravesical Bacillus Calmette-Guérin (BCG) and interferon- $\alpha$ 2A for the prevention of recurrence and progression in these patients.

Methods: We evaluated 58 patients with primary or recurrent non-muscle invasive bladder tumors followed by urology clinic between 1992 and 1996. The patients were divided into two groups: the BCG group $(n=29)$ and the interferon- $\alpha 2 A$ group $(n=29)$. The post-treatment recurrence rates were compared betweent the groups.

Results: A total of 58 patients, aged between 31 and 78 years (mean age, 59.1 years) was evaluated. Thirty eight patients had primary tumors and 20 had secondary tumors. Twenty-two patients had tumors in single locations and 36 had tumors in multiple locations. Our success rate was $82.8 \%$ in the BCG group and $48.3 \%$ in the interferon- $\alpha 2$ A group.

Conclusion: $B C G$ is the first and the most efficient agent for preventing the recurrence and progression of non-muscle invasive bladder cancers. Interferon- $\alpha 2 \mathrm{~A}$ can be used for the prevention of recurrence via intravesical application. However, its efficiency is low and the cost of treatment is high. Therefore, it is not recommend for routine use.
\end{abstract}

Keywords: Non-muscle invasive bladder cancer, Bacillus Calmette-Guérin, interferon- $\alpha$ 2A, immunotherapy

\section{ORCID IDs of the authors: A.I.H. 0000-0001-5193-2340; C.A. 0000-0001-9218-8562; O.C. 0000-0003-4586-7321; V.Ç. 0000-0001-7304-7190}

\section{INTRODUCTION}

Bladder cancer is the second most common cancer of the urogenital system (1). It is a significant mortality and morbidity problem with 350,000 new cases and 150,000 deaths annually worldwide. It is observed to be approximately three times more frequently in males than in females (2). Approximately $90 \%$ of bladder cancers have a urothelial origin. At the time of diagnosis, $70 \%-80 \%$ is classified as non-muscle invasive bladder cancer (NMIBC), and only $20 \%-30 \%$ is classified as muscle invasive bladder cancer. The mean age for the diagnosis is 65 years, and $1 \%$ of the cases are $<40$ years $(3-5)$.

Of the bladder cancer cases, 40\%-85\% usually recurs 6-12 months following the first resection (6). The most frequent recurrence is observed in carcinoma in situ with a rate of $82 \%$, and at least $30 \%$ is observed in solitary papillary tumors (7-8).

These high recurrence rates observed in NMIBC have necessitated the development of other treatments in addition to transurethral resection bladder tumor (TURBT). The drug used should be low cost, easy to find, easy to apply, and should have a minimum amount of side effect. Intracavitary chemotherapeutic or immunotherapeutic agents, which are used as an adjuvant therapy, form the base for this in NMIBC.

Thiotepa was first used in 1961 for this purpose, and mitomycin $\mathrm{C}$ and doxorubicin became available in time (9). Success rates increased with intravesical Bacillus Calmette-Guérin (BCG) therapy used in 1976 for the first time (10). In the 1990s, intracavitary use of interferons became a current issue. The goal is to prevent recurrence and protect the organ at the same time.

The aim of the present study was to compare the effectiveness of BCG and interferon- $\alpha$ 2A administered after TURBT in the prevention of recurrence in superficial bladder tumors in our clinic for the past 48 months.

\section{METHODS}

We compared the results of 58 patients who underwent TURBT for NMIBC and who received intracavitary BCG therapy or intracavitary therapy with interferon- $\alpha$ 2A at Gaziosmanpaşa Taksim Training and Research Hospital Urology Clinic of Health Sciences 
University between 1992 and 1996. This was a retrospectively designed study, and no ethics committee approval was required. The study was conducted in accordance with the World Medical Association Declaration of Helsinki ethical principles related to medical research on humans. Verbal consent was obtained from the patients. Approval for data use of patient files was also obtained. TURBT was primarily performed in patients who constituted the study group. Among the patients in whom NMIBC was detected in histopathological findings, the results of 29 patients who underwent BCG as an adjuvant therapy and 29 patients in whom interferon- $\alpha 2 \mathrm{~A}$ was administered were reviewed retrospectively.

Bacillus Calmette-Guérin was started to be administered on days 15-20 following resection. All patients were examined in terms of urinary tract infections prior to the application. Those who were infected were treated according to the result of culture antibiogram, and the application was postponed until the urine became sterile.

The application was performed by delivering $150 \mathrm{mg}$ of Pasteur Strain BCG (Pasteur, Paris, France) diluted in $50 \mathrm{~mL}$ isotonic water through a no. 8 nutritional probe placed in the bladder under sterile conditions. After the fluid remained in the bladder for 2 $\mathrm{h}$ (the patient was placed in supine, prone, right, and left lateral decubitus positions with 30-minute intervals), the patient was instructed to urinate. BCG was administered for 6 weeks, and later, one dose was administered in month 3 and one in month 6 as a booster; thus, a total of eight doses were administered.

Cystoscopic control was performed once in every 3 months in the first year, once in every 6 months in the second year, and then once in a year. Patients in whom tumor was detected on cystoscopy were accepted as recurrence, and necessary treatments were performed.

After dilution in $50 \mathrm{~mL}$ isotonic water, 54 million units of interferon- $\alpha$ 2A (Roferon-A; Roche Laboratories, Nutley, NJ, USA) was applied once a week through a no. 8 nutritional probe for 8 weeks. The positions of the patients during the application and subsequent follow-up schemes were the same as the BCG application.

Dysuria developed in 26 (89.6\%) patients in whom BCG was administered, and pollakiuria was observed in 26 (89.6\%) patients. These types of irritative symptoms usually occurred in the first 3 days following administration. The symptoms regressed spontaneously or improved with anticholinergic and/or anti-inflammatory drugs. Two patients with BCG cystitis were given isoniazid. Hematuria developed in 11 (37.9\%) patients, but it regressed spontaneously. Fever not exceeding $38^{\circ} \mathrm{C}$ was observed in six patients. Recovery was provided with antipyretics.

\section{Statistical Analysis}

The distribution of variables was measured using the Kolmogorov-Smirnov test. Independent samples t test and MannWhitney $U$ test were used for the analysis of quantitative independent data. Chi-square test was used for the analysis of qualitative independent data. Fisher's exact test was used when chi-square test conditions could not be provided.

\section{RESULTS}

Transurethral resection bladder tumor was performed in 58 patients with NMIBC, and intravesical treatment was applied with BCG or interferon- $\alpha 2 A$ in these patients. There were 48 male and 10 female patients. The mean age of the patients was between 31 and 78 (59.1) years. Of the patients, 38 had a primary tumor, and 20 had a recurrent tumor (Table 1).

Of the patients, 18 had stage Ta, and 40 had stage T1. Tumor grading was consistent with the Mostofi classification.

The patients were evaluated separately both after immunotherapy and in terms of the total follow-up periods. The total mean follow-up period of the patients was 10-132 (30) months. The mean follow-up period after immunotherapy was 8-53 (18) months.

Hematuria was the most common cause for patient consultation. In addition, there were prostatism complaints in 11 male patients and severe dysuria in 5 patients.

The total number of tumors in 58 patients was 101. Of these 101 tumors, $69(68.3 \%)$ were located in the side walls, $6(5.9 \%)$ in the

Table 1. Clinical and pathological characteristics of the patients

\begin{tabular}{|l|c|}
\hline Characteristics & Patients (n=58) \\
\hline Age (years) & 59.1 \\
\hline F/M ratio (\%) & $20.8 \%$ \\
\hline BMI (kg/m²) & 22.6 \\
\hline Smoking (\%) & $68.9 \%$ \\
\hline No. of tumors & 101 \\
\hline Tumor localization (\%) & \\
\hline - Lateral & $68.3 \%$ \\
\hline • Posterior & $5.9 \%$ \\
\hline • Dome and anterior & $14.8 \%$ \\
\hline • Bladder neck & $10.8 \%$ \\
\hline Tumor stage & \\
\hline • Ta & 18 \\
\hline • T1 & 40 \\
\hline Mean tumor diameter (cm) & $1.7 \mathrm{~cm}$ \\
\hline Primary tumor rate (\%) & $38(65.5 \%)$ \\
\hline Secondary tumor rate & $20(34.5 \%)$ \\
\hline Complications (\%) & \\
\hline • Dysuria-pollakiuria & $89.6 \%$ \\
\hline • Hematuria & $37.9 \%$ \\
\hline • Subfebrile fever & $10.3 \%$ \\
\hline • Orchitis & $3.4 \%$ \\
\hline Follow-up period (average) & $18 \mathrm{months}$ \\
\hline BMl: body mass index; F: female; M: male & \\
\hline
\end{tabular}


posterior wall, $11(10.8 \%)$ in the bladder neck, and $15(14.8 \%)$ in the fornix and front wall (Table 2).

Of the tumors, 48 were $0.5 \mathrm{~cm}, 30$ were $1 \mathrm{~cm}, 7$ were $1.5 \mathrm{~cm}, 11$ were $2 \mathrm{~cm}, 3$ were $3 \mathrm{~cm}$, and 2 were $4 \mathrm{~cm}$.

Bacillus Calmette-Guérin was applied in 29 patients, and interferon- $\alpha 2 \mathrm{~A}$ was applied in 29 patients whose data were evaluated.

Dysuria developed in 26 (89.6\%) patients, and pollakiuria in 26 (89.6\%) patients in whom BCG was administered. These complaints usually developed within the first 3 days after administration and regressed spontaneously or with anti-inflammatory and/or anticholinergic therapy. BCG cystitis symptoms that developed in two patients were regressed with the administration of isoniazid $300 \mathrm{mg} /$ day for 3 days.

Hematuria that developed in 11 (37.9\%) patients also regressed spontaneously without any additional intervention.

Of the patients, $6(10.3 \%)$ had fever not exceeding $38^{\circ} \mathrm{C}$. Orchitis developed in 1 (3.4\%) patient. BCG treatment was interrupted until orchitis treatment was started.

Recurrence was observed in 5 (17.2\%) patients in whom BCG was administered. One of them had previously received one cure of BCG. The tumor diameter was $1 \mathrm{~cm}$ in this patient, whereas the tumor diameters were $0.5 \mathrm{~cm}$ in the other four recurrent patients. Progression was seen in a patient with recurrence. The tumor progressed from T1G2 to T1G3. One of the recurrent patients was a patient who had been followed up for 11 years and had recurrences every 1-2 years. Ten patients had previously undergone TURBT due to NMIBC. The tumor developed again in 4 (40\%) of these patients. Our mean success rate was $82.8 \%$.

Table 2. Comparison of treatment groups in terms of clinical and pathological features

\begin{tabular}{|l|c|c|c|}
\hline & $\begin{array}{c}\text { BCG } \\
\text { group }\end{array}$ & $\begin{array}{c}\text { Interferon } \\
\text { group }\end{array}$ & $\mathbf{p}$ \\
\hline Age (years) & 58.1 & 60.2 & 0.752 \\
\hline F/M ratio & $16 \%$ & $26 \%$ & 0.486 \\
\hline BMl (kg/m²) & 22.3 & 22.8 & 0.882 \\
\hline Smoking (\%) & $65.1 \%$ & $72.4 \%$ & 0.570 \\
\hline No. of tumors & 53 & 48 & 0.360 \\
\hline Mean tumor diameter & 1.6 & 1.9 & 0.158 \\
\hline Tumor stage & & & \\
\hline \multicolumn{1}{|c}{ Ta } & 10 & 8 & \\
\hline \multicolumn{1}{|c|}{ T1 } & 19 & 21 & 0.667 \\
\hline Follow-up period (average) & 18 months & 19 months & 0.941 \\
\hline Recurrence rate & $17.2 \%$ & $51.7 \%$ & 0.005 \\
\hline BMl: body mass index; F: female; M: male & & \\
\hline
\end{tabular}

When the side effects of interferon- $\alpha 2 \mathrm{~A}$ were evaluated, there were 5 (17.2\%) dysurias and $5(17.2 \%)$ pollakiurias. Symptoms spontaneously regressed in the first $24 \mathrm{~h}$ after administration. Influenza-like symptoms were observed in 4 (13.7\%) patients. It recovered spontaneously in 2 days.

When data were analyzed, recurrence was observed in 15 (51.7\%) of the 29 patients who received interferon- $\alpha 2 A$. The success rate was $48.3 \%$ (Table 2). There was no progression in any of the patients. Ten of the patients in this group were patients who previously underwent TURBT. Recurrent tumors occurred in $5(50 \%)$ of these patients. Two of the patients who did not have recurrence and gave complete response were patients who had previously undergone TURBT and received one cure of BCG. No recurrence was observed in these patients after interferon- $\alpha 2 A$ administration.

\section{DISCUSSION}

Transurethral resection is the primary treatment of NMIBC. Pathological staging should be made correctly with proper and complete resection. Residual disease and recurrence risk exist even in low-grade tumors, and current applications to minimize this are intracavitary chemotherapy or immunotherapy.

In general, the diameter, number, and grade of the tumors and the number of recurrences are important to determine the prognosis $(11,12)$.

While the recurrence was found at $18 \%$ in solitary Ta tumors and at $33 \%$ in $\mathrm{T} 1$ tumors, it was found at $43 \%$ and $46 \%$ in multiple tumors, respectively (13). This ratio is $66 \%$ in our series.

Recurrence rate in the first 1 year in tumors $>3 \mathrm{~cm}$ in diameter is much higher than that in smaller ones. In our study, recurrence was seen in 3 of $7(42 \%)$ cases with tumors $>3 \mathrm{~cm}$ and in 17 of 52 (32\%) cases with tumors $<3 \mathrm{~cm}$.

There are chemotherapeutic or immunotherapeutic agents to be used as intracavitary agents after endoscopic treatment of the tumors in the mucosa and the ones limited in the lamina propria. BCG is the most effective agent among them (10). The most important aspect for BCG to be effective is its close contact with the tumor cells. Intracavitary application is done for this.

The success rate with BCG ranges from $47 \%$ to $100 \%$. When our BCG series was examined, it was found to be $82.8 \%$ in the 8-53-month follow-up period (average 27 months). We attribute our high rates to the two boosters we administered. However, we believe that there is a need for further studies to be conducted with a larger number of participants.

The patients in whom interferon- $\alpha 2 \mathrm{~A}$ was administered constituted the second group of the study. Standard dose and duration of administration have not yet been established in studies conducted with this agent. In our study group, 54 million units of interferon- $\alpha$ 2A was administered weekly for 8 weeks. The success rate was $48.3 \%$ in the 18 -month follow-up period. In our country, interferon- $\alpha 2 \mathrm{~A}$ is relatively more difficult to obtain and seems to be quite an expensive agent in comparison with BCG. 


\section{CONCLUSION}

Bacillus Calmette-Guérin is the primary drug for intracavitary use in the prevention of recurrences of non-muscle invasive bladder tumors after TURBT. Although the highest success can be achieved with this agent, we believe that interferon- $\alpha 2 \mathrm{~A}$ is an alternative agent that can be preferred due to a quite low side effect profile, though its effect is relatively low in cases where it cannot be used.

Ethics Committee Approval: Authors declared that the research was conducted according to the principles of the World Medical Association Declaration of Helsinki "Ethical Principles for Medical Research Involving Human Subjects", (amended in October 2013).

Informed Consent: Verbal informed consent was obtained from patients who participated in this study

Peer-review: Externally peer-reviewed.

Author Contributions: Concept - C.A., A.I.H.; Design - C.A.; Supervision - C.A.; Data Collection and/or Processing - O.C.; Analysis and/or Interpretation - V.Ç.; Literature Search - V.Ç.; Writing Manuscript - A.I.H.; Critical Review - O.C.

Conflict of Interest: No conflict of interest was declared by the authors.

Financial Disclosure: The authors declared that this study has received no financial support.

\section{REFERENCES}

1. Matanoski GM, Elliot EA. Bladder cancer epidemiology. Epid Rev 1981; 3: 203-29. [CrossRef]

2. Young JL Jr, Asine AJ, Pollack ES. Cancer Incidence and mortality in the united states (ed) Bethesta, M.D.78: 1837. DEHM Publication: Philadelphia.

3. Droller MJ. Transitional cell cancer of the bladder. Campbell's Urology II 1980; 124: 19.

4. Silverberg E. Cancer statistics, 1981. CA Cancer J Clin 1981; 31: 1328. [CrossRef]

5. Torti FM, Lum BL. Superficial carcinoma of the bladder: natural history and the role of interferons. Semin Oncol 1986; 13: 57-60.

6. Torti FM, Lum BL. Superficial bladder cancer. Risk of recurrence and potential role for interferon therapy. Cancer 1987; 59: 613-6. [CrossRef]

7. Utz DC, Hanash KA, Farrow GM. The plight of the patient with carcinoma in situ of the bladder. J Urol 1970; 103: 160-4. [CrossRef]

8. Lerman RI, Hutter RV, Whitmore WF Jr. Papilloma of the urinary bladder. Cancer 1970; 25: 333-42. [CrossRef]

9. Soloway MS. Rationale for intensive intravesical chemotherapy for superficial bladder cancer. J Urol 1980; 123: 461-6. [CrossRef]

10. Morales A, Eidinger D, Bruce AW. Intracavitary Bacillus CalmetteGuerin in the treatment of superficial bladder tumors. J Urol 1976; 116: 180-3. [CrossRef]

11. Friedell GH, Nagy GK, Cohen SM. Pathology of human bladder cancer and related lesion (eds.) Bryan GT, Cohen SM. (ir) pathology of bladder cancer, pp.11-42, CRC Press: Florida, 1984.

12. Pocock RD, Ponder BA, O'Sullivan JP, Ibrahim SK, Easton DF, Shearer RJ. Prognostic factors in non-infiltrating carcinoma of the bladder: a preliminary report. Br J Urol 1982; 54: 711-5. [CrossRef]

13. Lutzeyer W, Rübben H, Dahm H. Prognostic parameters in superficial bladder cancer: an analysis of 315 cases. J Urol 1982; 127: 250-2. [CrossRef] 